\title{
Sistem Pengontrol Nomor Antrian Menggunakan Smartphone Android
}

\author{
Lukas B. Setyawan'1, Gunawan Dewantoro², Sebastian Hermawan Prasetyo ${ }^{3}$ \\ Program Studi Teknik Elektro, \\ Fakultas Teknik Elektronika dan Komputer, \\ Universitas Kristen Satya Wacana, Salatiga \\ 1lukas.setyawan@staff.uksw.edu, ${ }^{2}$ gunawan.dewantoro@staff.uksw.edu, \\ ${ }^{3}$ sebastianhermawan@ymail.com
}

\section{Ringkasan}

Sistem pengontrol nomor antrian menggunakan smartphone android ini memanfaatkan jaringan wifi sebagai media komunikasi. Sistem menampilkan nomor antrian dari 01 hingga 99 dan mampu melayani sebanyak 9 loket layanan. Untuk menampilkan informasi ke pengantri digunakan matriks LED untuk menampilkan pesan berjalan sebanyak 10 karakter. Sistem terdiri atas dua bagian, yaitu Penampil untuk menampilkan nomor antrian, nomor loket serta penampil pesan berjalan dan Loket Layanan tempat petugas mengatur urutan nomor antrian melalui sentuhan pada layar smartphone android yang sudah ditanam program pengatur antrian di dalamnya. Sistem bekerja pada platform Android 1.6 ke atas. Mekanisme pengambilan kartu nomor antrian dilakukan secara terpisah dari sistem.

Kata kunci: pengontrol nomor antrian, smartphone android, jaringan wifi, pesan berjalan

\section{Pendahuluan}

Sistem antrian di lokasi pelayanan publik sangat diperlukan agar proses layanan berlangsung tertib dan lancar. Sistem antrian yang tidak efisien akan mengakibatkan proses layanan terganggu dan tidak lancar sehingga memicu keibutan antar pengantri. Apabila loket layanan hanya satu maka antrian akan sangat panjang, sebaliknya penambahan loket layanan justru akan menyebabkan para pengantri saling serobot seandainya sistem antrian tidak dikelola secara benar. Dengan pengaturan sistem antrian secara elektronik diharapkan proses pelayanan dapat berlangsung secara tertib dan lancar sehingga para pengantri merasa nyaman. Proses pelayanan dapat diperlancar dengan menambah jumlah loket layanan meski harus diimbangi dengan sistem pengaturan antrian secara benar. Untuk memperlancar proses pelayanan dan mempermudah proses koordinasi antar loket ketika memanggil nomor antrian maka dibuat suatu sistem elektronik. Pemanggilan yang dilakukan oleh masing-masing petugas loket layanan diatur oleh program yang ditanam di smartphone yang diletakkan di masing-masing loket. Agar tidak menggangggu manajemen ruang dan demi estetika ruang maka komunikasi dari tiap loket layanan ke tampilan nomor antrian dilakukan secara nir-kabel melalui jaringan wifi. Karena menggunakan sistem nir-kabel maka instalasinya tidak merepotkan dan juga akan lebih mudah diterapkan ke berbagai bentuk ruang. 
Pembahasan dimulai dengan penjelasan sistem antrian meliputi proses kerja sistem, sistem perangkat keras, dan sistem perangkat lunak. Kemudian dilanjutkan dengan hasil pengujian dan diakhiri dengan kesimpulan.

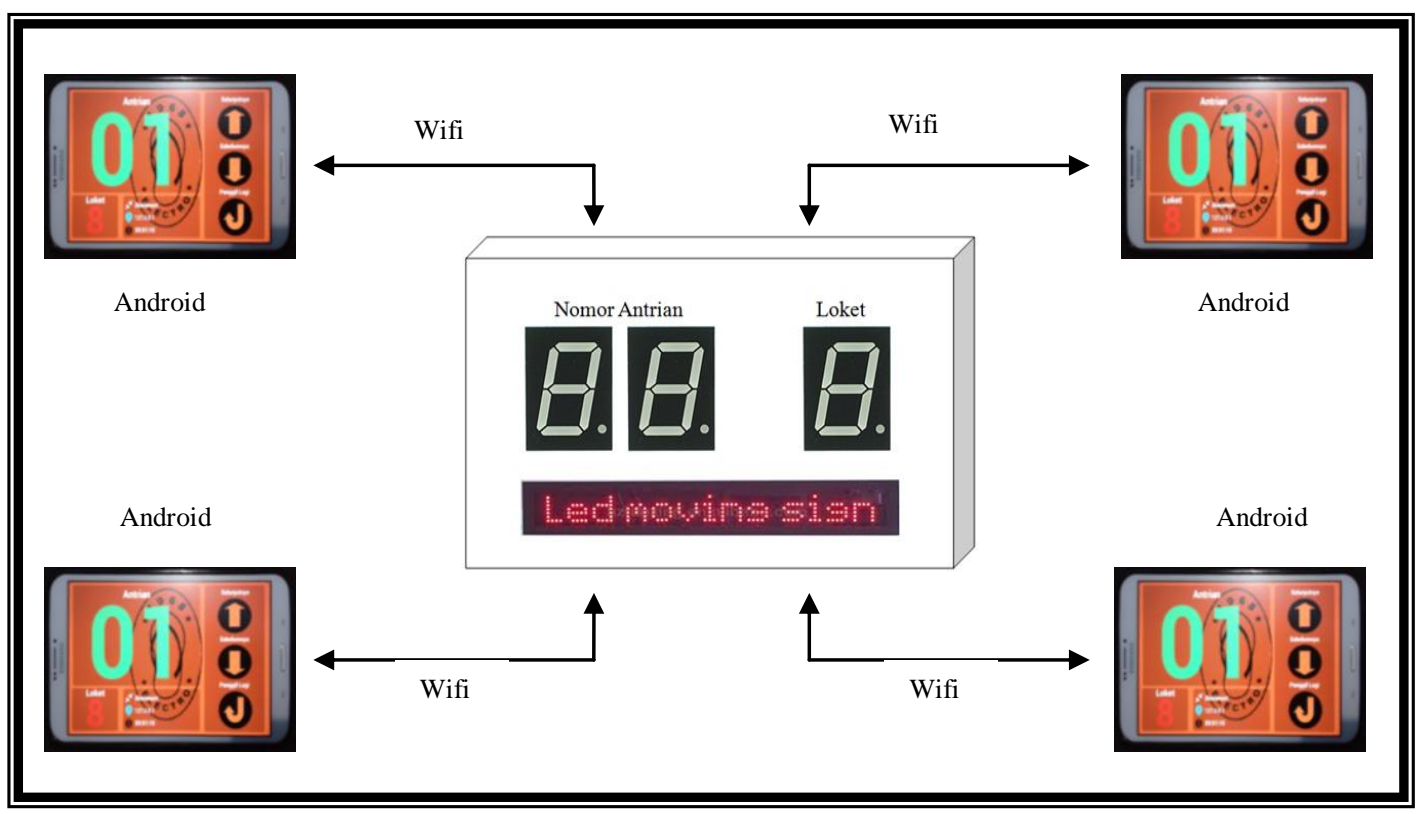

Gambar 1. Konfigurasi sistem antrian

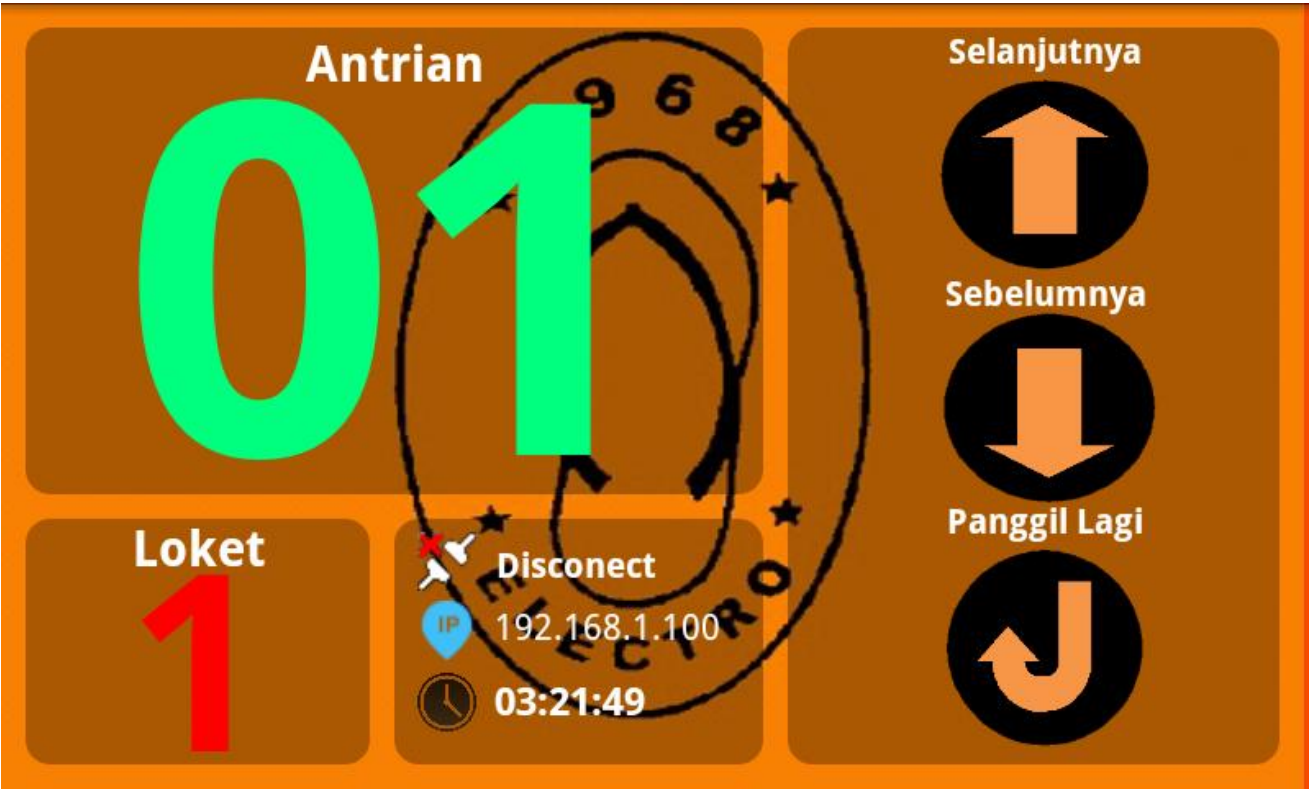

Gambar 2. Contoh tampilan layar smartphone yang ada di Loket Layanan

\section{Sistem Antrian}

Sistem antrian ini terdiri dari penampil untuk menampilkan nomor antrian, nomor loket, serta pesan berjalan sepanjang 10 karakter dan Loket Layanan dimana petugas memerintahkan nomor antrian berikutnya di loket tersebut melalui sentuhan tombol di layar smartphone. Sistem mampu melayani sebanyak 9 Loket Layanan. Komunikasi dari Loket Layanan ke Penampil dilakukan lewat jaringan wifi. Konfigurasi sistem antrian 
diperlihatkan oleh Gambar 1. Contoh tampilan layar smartphone yang ada di masingmasing Loket Layanan ditunjukkan oleh Gambar 2.

\subsection{Proses Kerja Sistem}

Prinsip sistem pengontrol nomor antrian pada dasarnya adalah untuk memperlancar dan mempermudah petugas ketika mengurutkan giliran para pengantri untuk mendapatkan pelayanan. Apabila proses antrian berlangsung tertib, teratur, dan lancar serta adanya petunjuk dan informasi yang jelas ke loket mana pengantri harus menuju maka para pengantri akan merasakan kenyamanan pada saat menunggu giliran dan pada saat mendapat layanan. Untuk itu sistem ini menyediakan Penampil dengan ukuran yang cukup besar agar bisa terbaca jelas dalam jarak pandang cukup jauh yang menampilkan nomor antrian yang mendapat kesempatan layanan dan nomor loket ke mana pengantri harus menuju. Setiap petugas selesai memberikan layanan di masingmasing Loket Layanan maka petugas menyentuh tombol di layar smartphone untuk memanggil nomor antrian berikutnya. Perintah ini akan dikirimkan ke Penampil sehingga nomor antrian berikutnya dan nomor Loket Layanan akan ditampilkan di Penampil. Nomor antrian ini juga akan dikirimkan ke smartphone di semua Loket Layanan. Setiap pergantian giliran ke nomor antrian berikutnya diberi tanda melalui suara buzzer sehingga diketahui oleh para pengantri. Pengantri yang memiliki nomor antrian sesuai dengan nomor antrian di Penampil akan mendapat layanan di nomor Loket Layanan sesuai dengan nomor loket di Penampil. Bagan kotak sistem diperlihatkan oleh Gambar 3. Tampilan bagian Penampil dan tampilan smartphone di bagian Loket Layanan dapat dilihat pada Gambar 4.

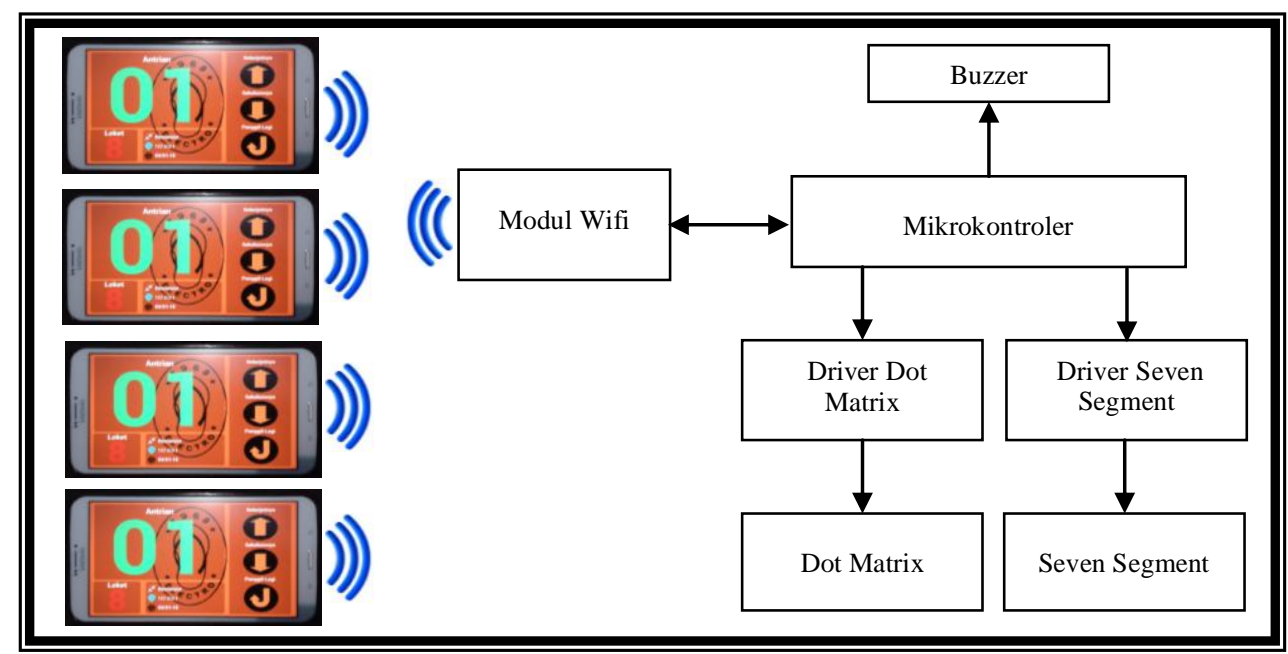

Gambar 3. Bagan kotak sistem

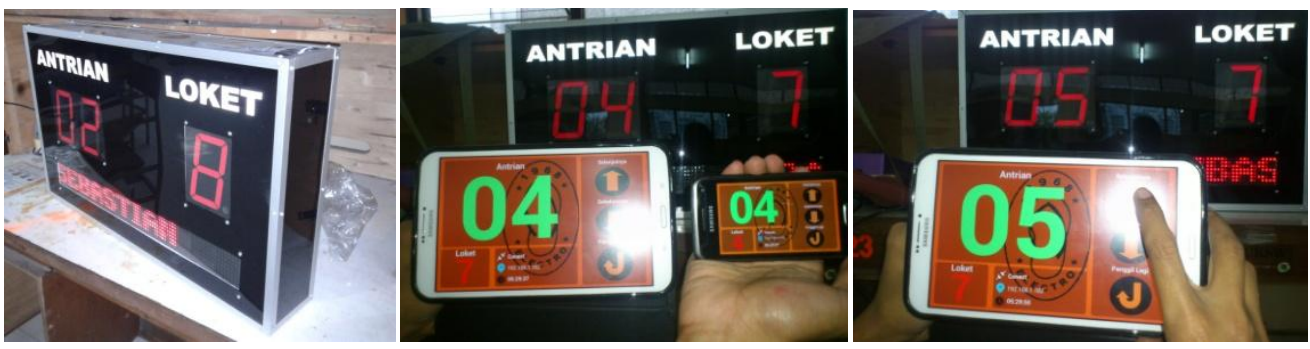

Gambar 4. Tampilan bagian penampil dan tampilan di layar smartphone 


\subsection{Sistem Perangkat Keras}

Perangkat keras terdapat di bagian Penampil yang terdiri atas tiga bagian utama, yaitu Pengendali Pusat, Penampil Seven-Segment, dan Penampil Pesan Berjalan.

Pada Pengendali Pusat terdapat mikrokontroler Atmega328 yang berfungsi untuk menerima perintah dari smartphone di masing-masing Loket Layanan melalui jaringan wifi dan setelah data diolah kemudian dikirimkan ke Penampil Seven-Segment dan ke semua smartphone yang ada di Loket Layanan. Agar mikrokontroler dapat berkomunikasi dengan smartphone digunakan modul wifi USR-WIFI232B. Modul wifi USR-WIFI232B terhubung ke mikrokontroler melalui kaki serial Tx-Rx. Lihat Gambar 5.

Gambar 6 memperlihatkan skema Penampil Seven-Segment sedangkan skema Penampil Pesan Berjalan ditunjukkan oleh Gambar 7.

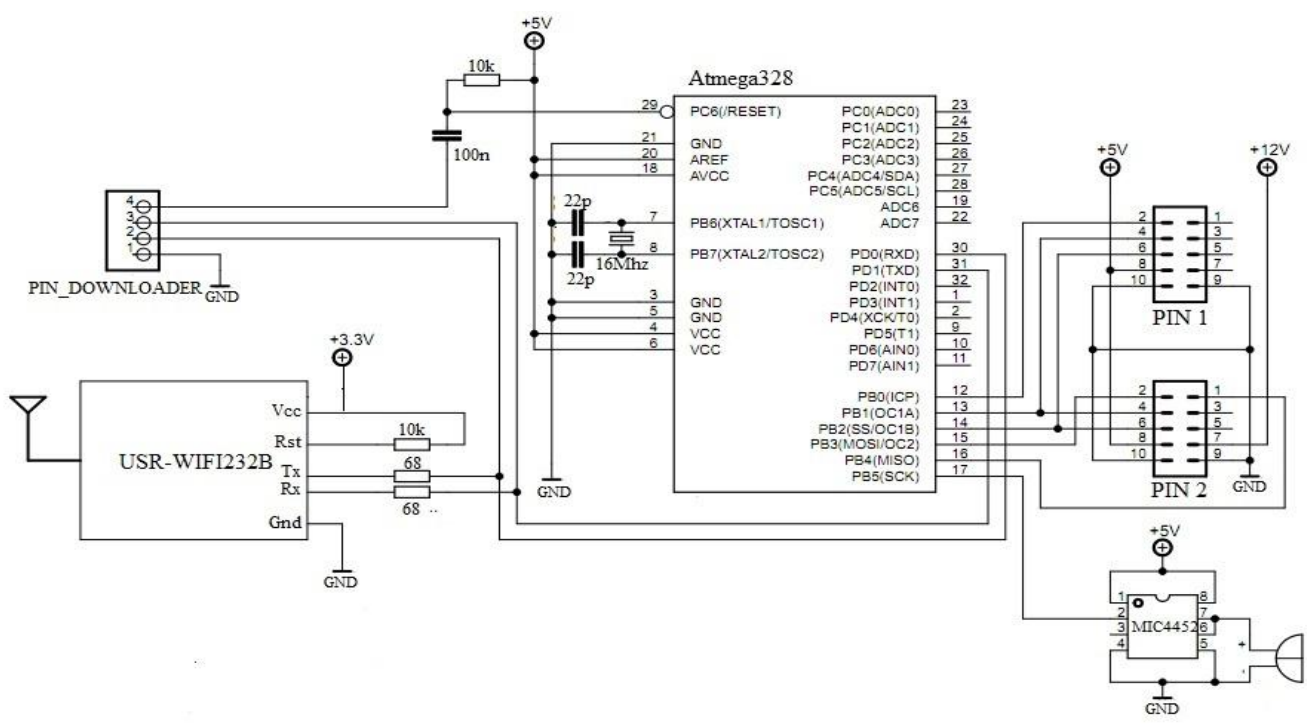

Gambar 5. Skema bagian Pengendali Pusat

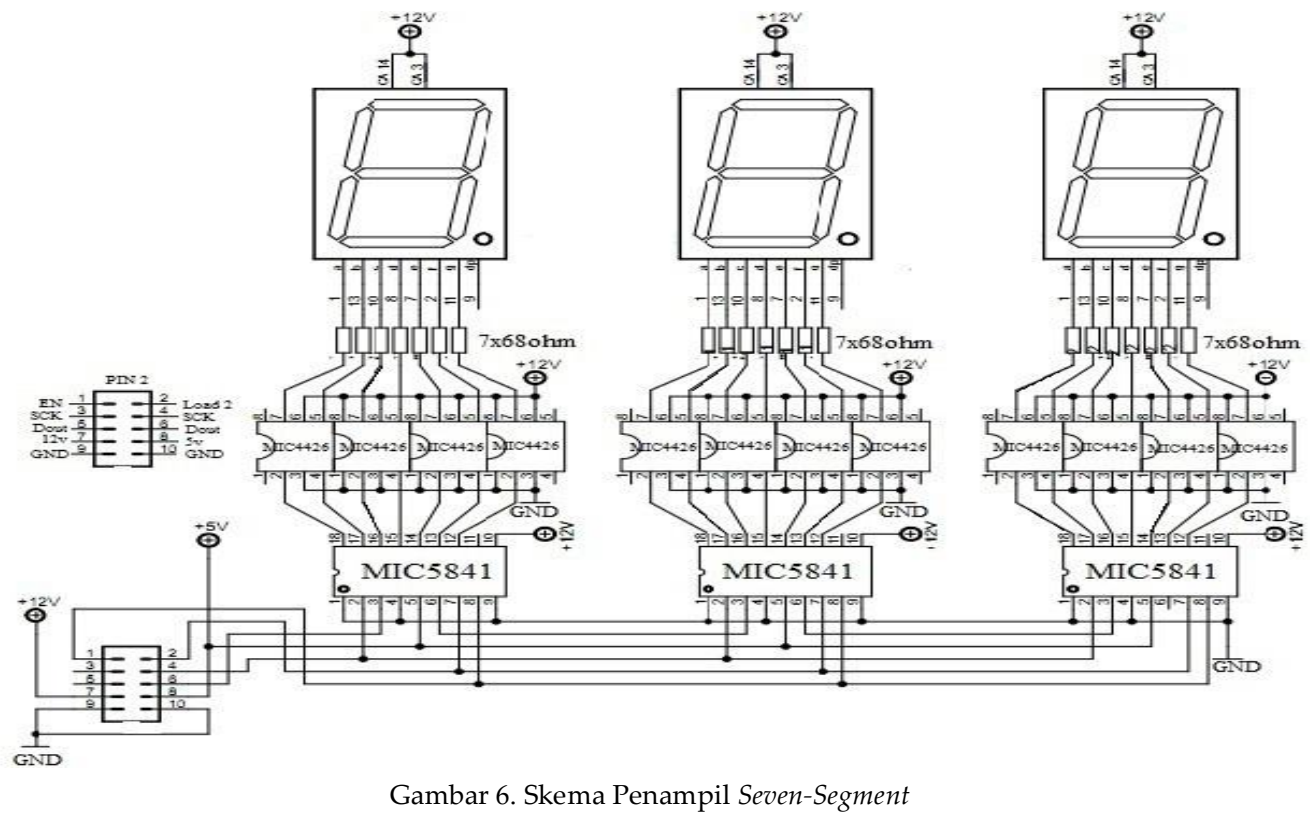


Sistem Pengontrol Nomor Antrian Menggunakan Smartphone Android Lukas B. Setyawan, Gunawan Dewantoro, Sebastian Hermawan Prasetyo

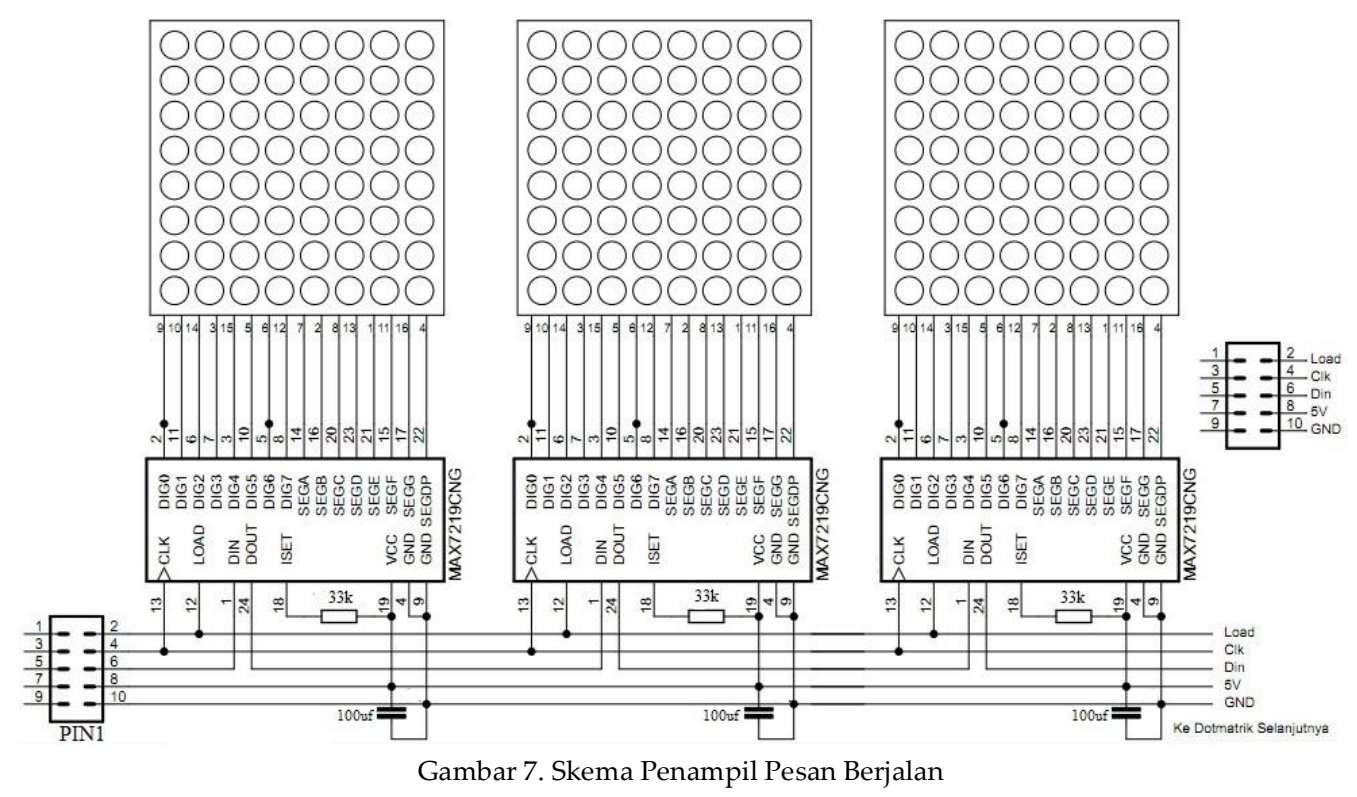

\subsection{Sistem Perangkat Lunak}

Sistem perangkat lunak terbentuk dalam dua perangkat lunak. Perangkat lunak pertama ditanam di bagian Pengendali Pusat. Perangkat lunak kedua diimplementasikan sebagai program aplikasi yang ditanam di smartphone yang berfungsi untuk melakukan interaksi antara sistem dan operator Loket Antrian. Perangkat lunak Pengendali Pusat ditanam di mikrokontroler Atmega328 yang akan mengatur proses antrian dengan bagan alir Gambar 8.

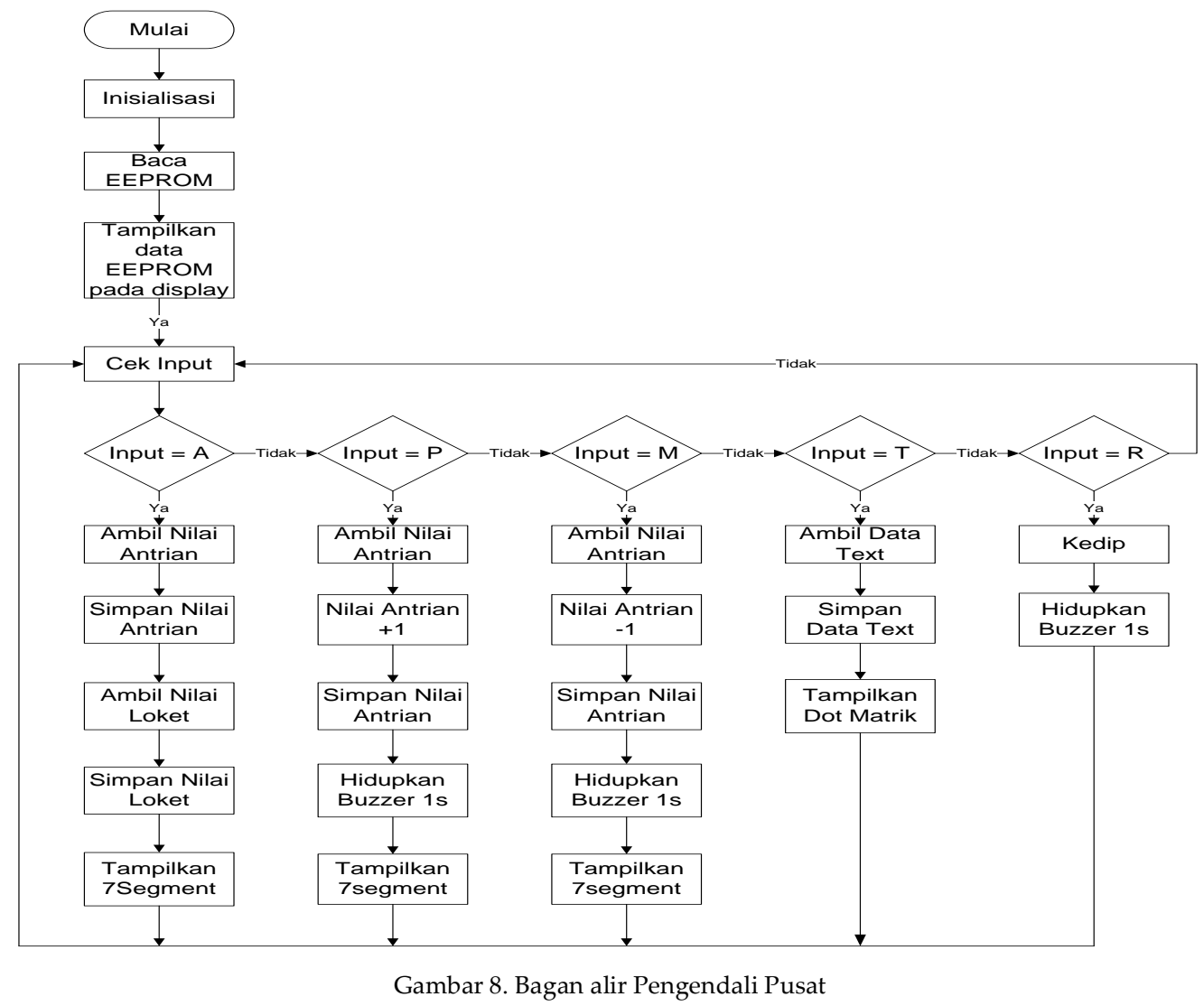




\section{Hasil Pengujian}

Pengujian sistem dilakukan dengan menanam program aplikasi di smartphone Android dengan platform Android 1.6 ke atas. Pengujian sistem menunjukkan bahwa program aplikasi berhasil diimplementasikan menggunakan perangkat smartphone Samsung Galaxy W (2.3.6), Sony Erricson Experia Arc (4.1.1), dan Samsung Galaxy Tab 3 8" (4.2.2). Ketiga perangkat ini dapat bekerja secara bersamaan. Dari pengujian diperoleh jarak antara Penampil ke smartphone (Loket Layanan) paling jauh adalah 30 meter.

\section{Kesimpulan}

Sistem pengontrol antrian telah berhasil direalisasikan menggunakan perangkat smartphone Samsung Galaxy W (2.3.6), Sony Erricson Experia Arc (4.1.1), dan Samsung Galaxy Tab 3 8" (4.2.2). Sistem akan dikembangkan untuk implementasi berbagai macam Loket Layanan.

\section{Daftar Pustaka}

[1] S. H. Prasetyo, Sistem Pengontrol Nomor Antrian dan Moving Sign Display Dengan Smartphone Android Dengan Media Koneksi WiFi, Salatiga: Fakultas Teknik Elektronika dan Komputer, Universitas Kristen Satya Wacana, 2014.

[2] N.D. Purwanto, Sistem Monitoring Ruangan Serta Kontrol Lampu Menggunakan Smartphone Android Dengan Media Komunikasi Jaringan Wi-Fi, Salatiga: Fakultas Teknik Elektronika dan Komputer, Universitas Kristen Satya Wacana, 2012. 